\title{
Global research trends of obstructive sleep apnea from 2011 to 2020: a 10-year bibliometric analysis
}

\author{
Lei Pan $^{1,2}$, Fanqi Meng ${ }^{1}$, Lei Zhang ${ }^{1}$, Hui Shen ${ }^{1}$, Delei Kong ${ }^{1}$, Wei Wang ${ }^{1}$, Jian Kang ${ }^{1}$ \\ ${ }^{1}$ Department of Respiratory and Critical Care Medicine, The First Affiliated Hospital of China Medical University, Shenyang, China; ${ }^{2}$ Liaoning \\ Provincial Centers for Disease Control and Prevention, Shenyang, China \\ Contributions: (I) Conception and design: L Pan; (II) Administrative support: W Wang, J Kang; (III) Provision of study materials or patients: L Pan, \\ H Shen; (IV) Collection and assembly of data: F Meng, D Kong; (V) Data analysis and interpretation: L Pan, L Zhang; (VI) Manuscript writing: All \\ authors; (VII) Final approval of manuscript: All authors. \\ Correspondence to: Wei Wang. Department of Respiratory and Critical Care Medicine, The First Affiliated Hospital of China Medical University, No. \\ 155, Nanjing North Street, Heping District, Shenyang 110001, China. Email: wwbycmu@126.com.
}

Background: Obstructive sleep apnea (OSA) is a common clinical condition with far-reaching health implications. We aimed to analyze the published articles of OSA and compare the differences in aspects of years, countries, institutions, journals, authors and keywords to evaluate the hotspots and development trends in OSA research.

Methods: We screened all associated literature on OSA from Web of Science (WoS) during 2011-2020 and analyzed the research trends in this field using the VOS viewer and the online bibliometric analysis platform. The BICOMB and gCLUTO softwares were used to visualize the hotspots in OSA research.

Results: We screened 24,291 compliant publications. Statistics show that the number of OSA-related publications has increased annually. The United States has been leading in the global research field of OSA. Sleep and breathing have published the most articles on OSA. The University of Pennsylvania is the most prolific research institution, while David Gozal has made significant OSA research contributions. Four research hotspots have been summarized through the 21 most common keywords: (I) operative treatment for children with OSA; (II) risk factors and diagnosis of adult OSA; (III) prevalence of OSA and positive airway pressure treatment; (IV) oxidative stress caused by intermittent hypoxia and complications of OSA such as cardiovascular disease and insulin-resistance. Keywords: "Biomarkers", "Endoscopy", "Bariatric surgery", "Oral appliance", "Oropharyngeal exercises", are gradually emerging in the field of OSA research.

Conclusions: Over the past decade, increasing attention has been paid to global OSA-related research. The United States is dominating in the OSA research. China possesses a considerable publication number now, which has grown rapidly in the last decade. However, more attention to publication-quality is needed. Instead of traditional therapies, oral appliance, oropharyngeal exercises and much more new approaches are proven to benefit OSA patients and gradually becoming research hotspots.

Keywords: Statistical bibliography; obstructive sleep apnea (OSA); hotspots; VOS viewer

Submitted Aug 11, 2021. Accepted for publication Dec 02, 2021.

doi: 10.21037/apm-21-2237

View this article at: https://dx.doi.org/10.21037/apm-21-2237

\footnotetext{
$\wedge$ ORCID: 0000-0002-6669-8144.
} 


\section{Introduction}

Obstructive sleep apnea (OSA) is a common clinical syndrome of hypoventilation or apnea events caused by recurrent narrowing or collapse of the airways during sleep (1). More than $25 \%$ of the population suffers from OSA in the United States, and similar prevalence rates have been found in other European and American countries (2). Repetitive partial or complete collapse of the upper airway during sleep contributing to intermittent hypoxia and hypercapnia, elevated markers of oxidative stress, and inflammation (3). Untreated OSA can lead to cardiovascular diseases, metabolic dysfunction, stroke, neurocognitive impairment, daytime sleepiness, and depression. These symptoms burden most patients and seriously negatively impact on social relationships, work performance, and quality of life (4). Monitoring breathing status during sleep is required to diagnose OSA. The methods commonly used in clinics can be divided into three categories: polysomnography (PSG), home sleep apnea testing (HSAT), and other auxiliary diagnostic tools, of which PSG is the gold standard for OSA diagnosis (5). There is no effective drug treatment for OSA, and the main treatment can be classified broadly into two categories: invasive and non-invasive. Of these, invasive treatments mainly involve surgical alteration of pharyngeal soft tissues or facial bones to widen the upper airway, including uvulopalatopharyngoplasty, maxillomandibular advancement, and multi-level salvage surgery $(6,7)$. As for the non-invasive, continuous positive airway pressure (CPAP) is still the main treatment for severe OSA (8). In recent years, oral appliances (mandibular advancement devices, MADs) are increasingly prescribed as a non-invasive treatment in OSA patients. MADs push the mandible and tongue to the anterior position, thereby expanding the upper airway and reducing collapse during sleep (9).

Bibliometric analysis is a new scientific method for assessing the contribution of countries, institutions, authors, and journals to the field of research. Additionally, bibliometric analysis can predict hotspots and trends in a research field through information visualization. In the last decade, with the development of technology, increasing numbers of researchers have devoted themselves to the field of sleep apnea. We conducted a comprehensive bibliometric analysis of the global OSA literature from 2011 to 2020, with statistical and visual analyses of publication numbers, national publications, international collaboration, institutions, journals, authors, and keywords. A global OSA research review was conducted using co-occurrence keywords over visualization plots and cluster analysis to identify the trends and hotspots in OSA research.

\section{Methods}

\section{Data sources and search strategies}

We conducted a comprehensive online search of the literature of OSA from 2011 to 2020 using Web of Science (WoS), which was widely accepted in bibliometric analysis. To avoid bias in database updates, all database searches were conducted on March 15, 2021. Search strategy was TS = ("Obstructive sleep apnea”, "Obstructive sleep apnea syndrome", "Sleep apnea, obstructive" or "Sleep apnea"), language was set to English, and literatures other than articles and reviews were excluded.

\section{Data collection}

Two authors (Lei Pan and Fanqi Meng) independently extracted all data of the included articles, including title, keywords, authors, institution, journal, publication date, country/region and citations. The retrieval agreement rate was calculated to be $98 \%[\mathrm{kappa}=(\mathrm{P} 0-\mathrm{Pe}) /(\mathrm{n}-\mathrm{Pe})$ $=0.98>0.75]$.

\section{Statistical analysis}

This study provided a comprehensive description of the publication characteristics of OSA over the last decade in terms of country, institutions, journals, authors, citations, keywords, Impact Factor (IF), Hirsch index (H-index) and relative research interest (RRI). IFs were all drawn from the Journal Citation Reports (JCR) published in 2021 and were used to assess the scientific value of research conducted in the literature. The H-index, widely considered to be a reflection of research impact among countries or scientists, with the meaning of " $\mathrm{H}$ " papers published by scientist or country and at least " $\mathrm{H}$ " times cited in other publications. The RRI was defined by the number of publications associated with a particular research field, and then was divided by the number of publications per year in all fields.

The bibliometric analysis was performed using the bibliometric online analysis platform (http://bibliometric. com) and VOS viewer 1.6.15 (Leiden University, Leiden, The Netherlands). Using GraphPad Prism 6 to visualize 


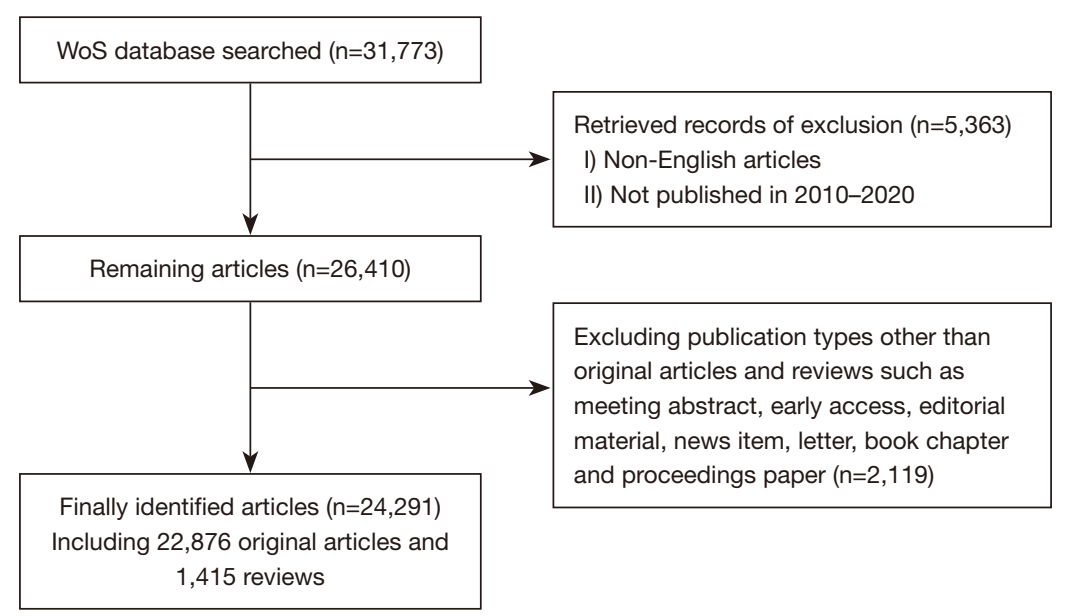

Figure 1 The flow chart of screening process in the research of obstructive sleep apnea. WoS, Web of Science.

annual and cumulative publication numbers of different countries and regions. VOS viewer was employed to analyze and visualize bibliometric web data such as authors, institutions, journals, and keywords. Using VOS viewer to generate network visualization plots and bibliometric visible images with timelines. Using online bibliometric analysis platform and Microsoft Excel 2016 to assess the influence of authors, institutions and journals. Then we imported the WoS filtered data to Bibliographic Item Cooccurrence Matrix Builder (BICOMB) to construct the keyword-article binary matrix. The rows of the matrix indicate the literatures that satisfied the inclusion criteria, while the columns indicate the recurrent keywords. After that, gCLUTO 1.0 software was applied to perform clustering algorithm analysis, constructing the respective volcano and heat maps that based on the clustering analysis results.

\section{Results}

\section{Global contribution and cooperation to publications on OSA}

According to the inclusion criterion, 24,291 OSA-related articles meeting the criteria were accepted for our study (Figure 1). We found that the number of publications on OSA increased annually (Figure 2A). The United States and China consistently lead in the number of publications (Figure 2B,2C), with Australia following behind (Figure 2D). By calculating the RRI value, we found that the number of publications on OSA has been maintained at a relatively high level after 2018 with RRI value approximately reaching
0.20 , which steadily kept increasing since 2011 from 0.15 (Figure $3 A$ ). The first echelon of countries on publications are as follows: the United States $(8,194,36.848 \%)$, China $(2,242,10.082 \%)$, Australia $(1,461,6.570 \%)$, Canada $(1,454$, $6.539 \%)$ and Italy $(1,417,6.372 \%)$ (Table 1$)$. The analysis of citations and H-index shows that the United States ranks first with 188,251 citations and $\mathrm{H}$-index of 140 . The second most cited country is Canada with 51.931 citations and an $\mathrm{H}$-index of 85. The third most cited country is Australia with 34,249 citations and an $\mathrm{H}$-index of 82 (Figure $3 B$ ). China, however, ranks second in the number of publications, but there is still a giant gap in the number of citations and $\mathrm{H}$-index compared to the above three countries (Figure 3B). The trends of the top 10 countries with the highest number of publications is shown in Figure 4.

\section{Institutions and authors publishing research on OSA}

The University of Pennsylvania (Univ Penn) has the highest number of publications of all institutions, with 708 total publications and 10,198 total citations. In terms of citations, Harvard University ranks first with 14,001. In the number of first-author publications, the University of Chicago (Univ Chicago) ranks first with 206 publications, which also ranks first in the total number of first-author citations $[3,870]$ and the average number of citations (18.79). Among the top 10 institutions, 7 are from the United States and the others are from Australia, Canada, and Brazil. The top 10 institutions with the most publications are shown in Table 2. VOS viewer visualization tool was used with the timeline of interinstitutional collaboration, the threshold for the minimum 

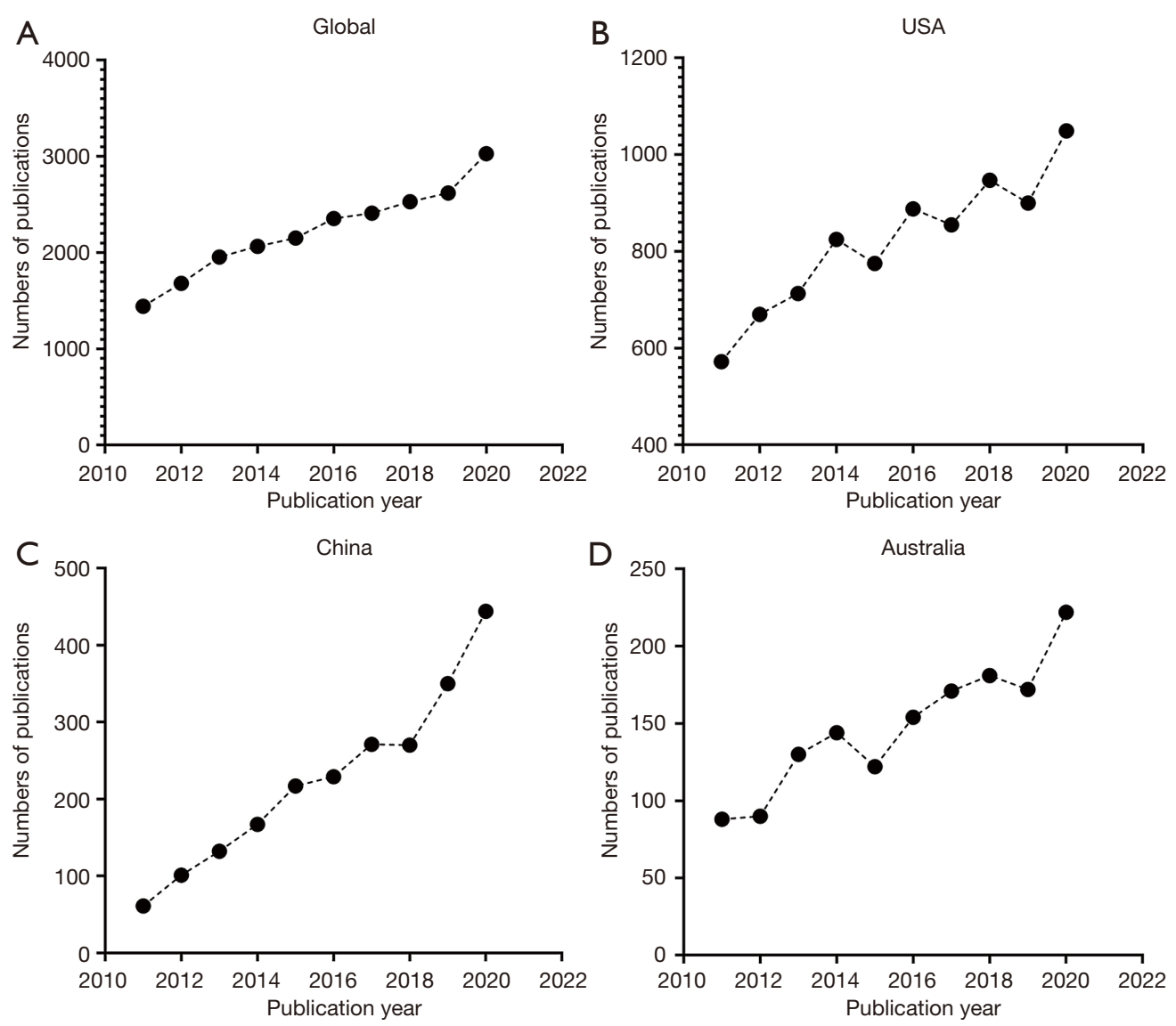

Figure 2 The trend of annual publications worldwide and top 3 countries on obstructive sleep apnea. (A) Global increasing trend on obstructive sleep apnea. (B) The United States keeps the most annual publications with an overwhelming number. (C) Publications on obstructive sleep apnea of China is surging. (D) Australia has a relatively slow growth rate on publication.
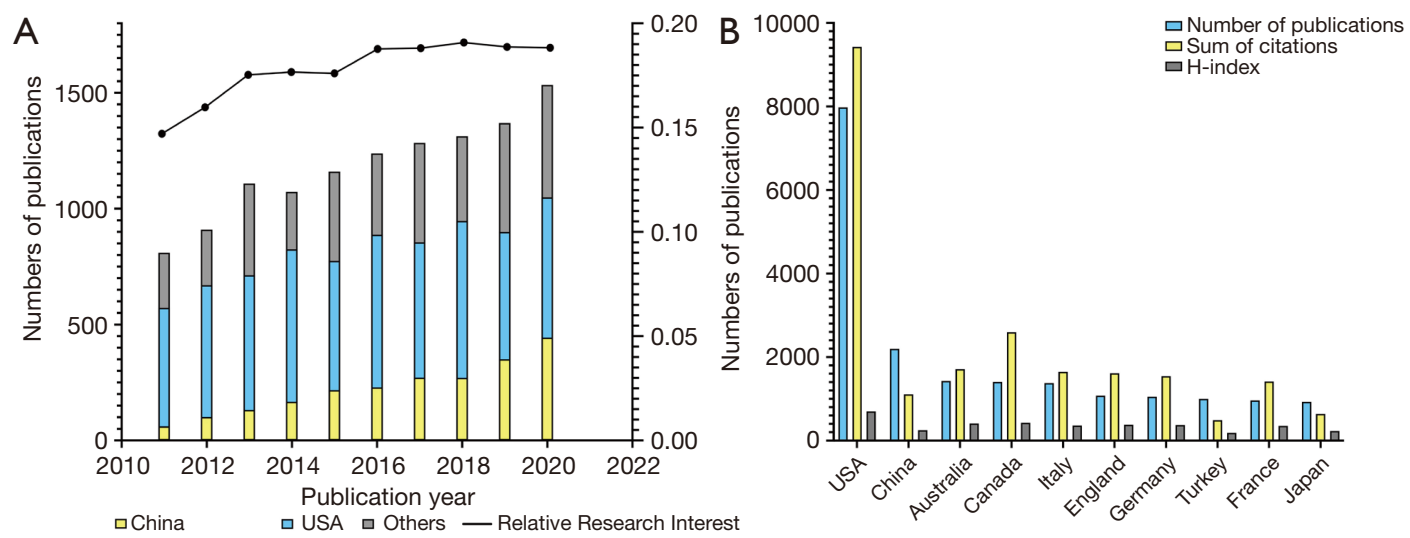

Figure 3 Articles related to obstructive sleep apnea published worldwide. (A) The annual publications and relative research interest (RRI) on worldwide. (B) The number of publications, citation frequency (actual value $\times 0.05$ ), and H-index (actual value $\times 5)$ in the top 10 countries or regions. 
number of literatures published per institution was set to 100 , and the threshold for the minimum number of citations was set to 2000. Finally, we identified 62 institutions that reach the threshold (Figure $5 A$ ).

David Gozal (University of Missouri) from the United States has made outstanding contributions to OSA research. He ranks first in the world in terms of total article counts,

Table 1 Ten countries with the most sleep apnea related publications worldwide

\begin{tabular}{lccc}
\hline Rank & Country/region & Records & Percentage \% (N=24,291) \\
\hline 1 & USA & 8,194 & 36.848 \\
2 & China & 2,242 & 10.082 \\
3 & Australia & 1,461 & 6.570 \\
4 & Canada & 1,454 & 6.539 \\
5 & Italy & 1,417 & 6.372 \\
6 & UK & 1,114 & 5.010 \\
7 & Germany & 1,092 & 4.911 \\
8 & Turkey & 1,025 & 4.609 \\
9 & France & 990 & 4.452 \\
10 & Japan & 953 & 4.286 \\
\hline
\end{tabular}

first author counts, corresponding author counts and $\mathrm{H}$-index. Among the top 10 authors in terms of publication number, David Gozal leads the list with 234 publications, followed by Susan Redline (Harvard Medical School) from the US and Jean-Louis Pepin (Universite Grenoble Alpes) from France with 194 and 175 publications respectively. The details are shown in Table 3. VOS viewer visualization tool was used with the timeline for inter-author collaboration, the threshold for the minimum number of publications per author was set to 35 , and the threshold for minimum number of citations per author was set to 2,000. Finally, we identified 38 authors who met the threshold (Figure 5B).

\section{Fournals publishing researches on OSA}

Among the top 10 journals, Sleep and Breathing (IF 2.816) ranks first with 12,97 publications, followed by fournal of Clinical Sleep Medicine (IF 4.062) with 815 publications. Sleep Medicine (IF 3.492), Sleep (IF 5.849) and PLoS One (IF 3.24) rank third, fourth and fifth, with 808/601/409 publications respectively. Although the total number of publications ranking fourth with 601 , Sleep is the highest journal in terms of both citation frequency and $\mathrm{H}$-index and has a higher impact among all OSA-related journals (Table 4).

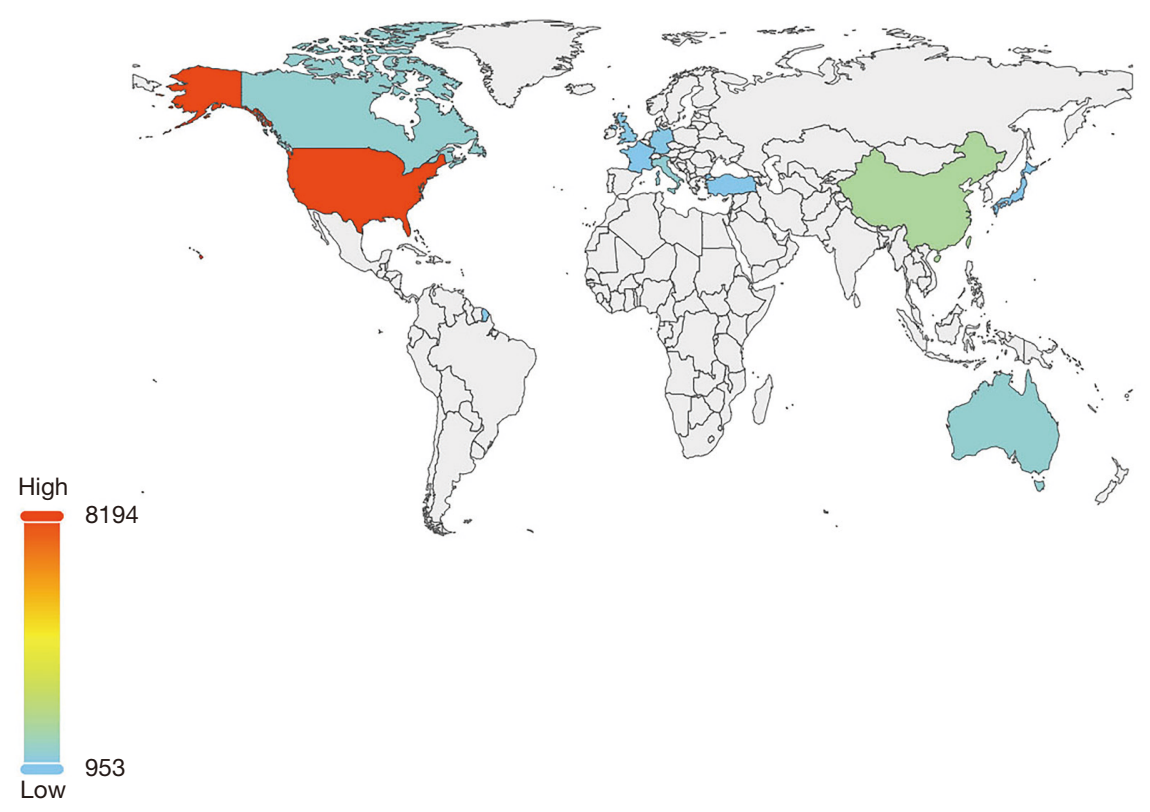

Figure 4 Worldwide publication trends of research on obstructive sleep apnea. The red areas indicate the countries and regions with the highest number of publications, and the blue indicate the lowest. The uniform grey areas represent relatively less publications on Web of Science $\left(W_{0 S}\right)$ or missing data. 
Table 2 Ten most productive institutions on obstructive sleep apnea

\begin{tabular}{|c|c|c|c|c|c|c|c|}
\hline Rank & Institutions & $\begin{array}{l}\text { Article } \\
\text { counts }\end{array}$ & $\begin{array}{l}\text { Total number } \\
\text { of citations }\end{array}$ & $\begin{array}{c}\text { Average number } \\
\text { of citations }\end{array}$ & $\begin{array}{l}\text { Total number of } \\
\text { first author }\end{array}$ & $\begin{array}{c}\text { Total number of first } \\
\text { author citations }\end{array}$ & $\begin{array}{l}\text { Average number of first } \\
\text { author citations }\end{array}$ \\
\hline 1 & Univ Penn & 708 & 10,198 & 14.4 & 174 & 2,016 & 11.59 \\
\hline 3 & Univ Toronto & 674 & 9,234 & 13.7 & 142 & 2,404 & 16.93 \\
\hline 6 & Harvard Univ & 575 & 14,001 & 24.35 & 94 & 1,570 & 16.7 \\
\hline 7 & Univ Michigan & 570 & 6,732 & 11.81 & 133 & 962 & 7.23 \\
\hline 8 & Univ Sao Paulo & 562 & 5,998 & 10.67 & 173 & 1,907 & 11.02 \\
\hline
\end{tabular}

A
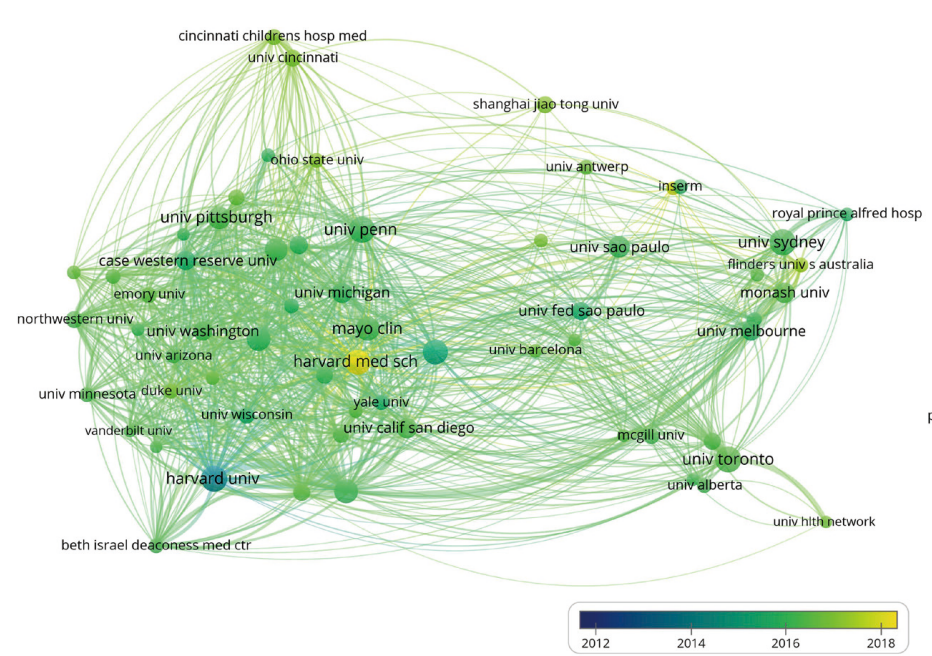

B

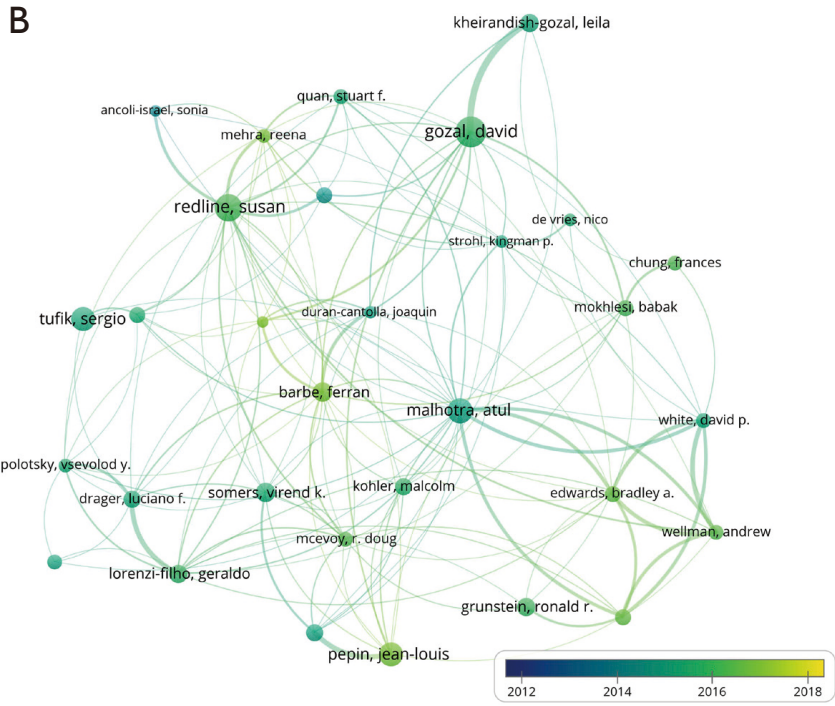

Figure 5 International-institutions and authors collaboration on obstructive sleep apnea. (A) International-institutions collaboration on obstructive sleep apnea. (B) Authors collaboration on obstructive sleep apnea.

\section{Citations publishing researches on OSA}

In aspect of reference citations, "The occurrence of sleepdisordered breathing among middle-aged adults" (10) published by Young et al. in 1993 in the New England Fournal of Medicine (IF 74.699), is the most cited article with 2,336 cumulative citations. In the second and third place are "A new method for measuring daytime sleepiness: the Epworth sleepiness scale" (11) published by Johns et al. in 1991 in Sleep (IF 4.805), and "Long-term cardiovascular outcomes in men with OSA - hypopnea with or without treatment with CPAP: an observational study" (12) published by Marin et al. in 2005 in Lancet (IF 60.392), with 2,170 and 1,566 citations respectively (Table 5).

\section{Analysis of keywords in OSA}

We used VOS viewer to analyze all the 24,291 articles included. A total of 431 keywords (defined by the terms appearing more than 75 times in the titles and abstract 
Table 3 Ten most productive authors on obstructive sleep apnea

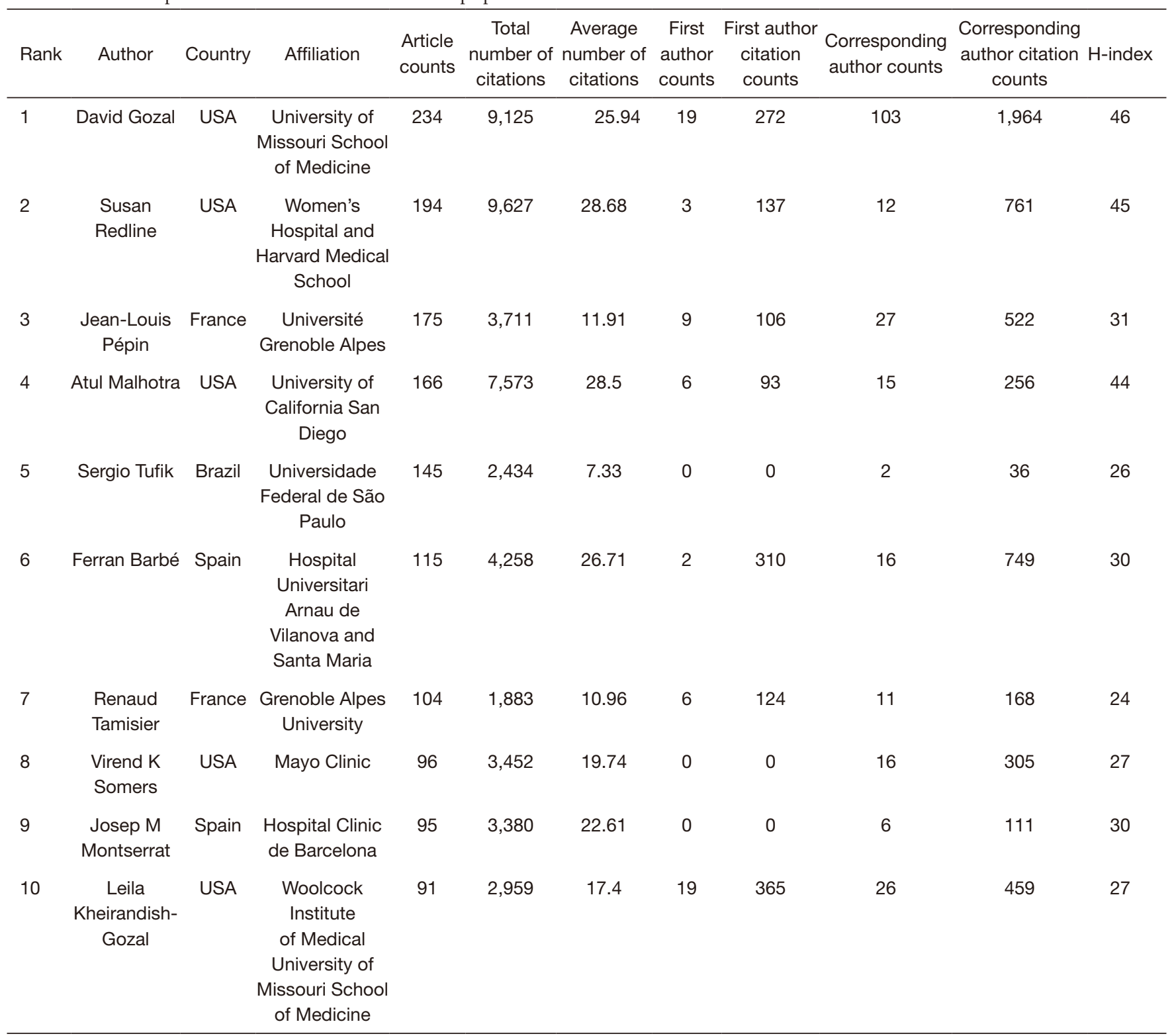

of all publication) were divided into two groups: "clinical research" (right, red) and "basic research" (left, green) (Figure 6A), then the visualization tool was used with the timeline of the inter-author collaboration for keyword visualization (Figure 6B). The 21 most common keywords from the included publications were extracted and displayed in Table 6. Cluster analysis was performed by gCLUTO to the above 21 keywords and the cluster number was set as 4 , forming a total of 4 clusters of $0,1,2$, and 3 . Then matrix and volcano plots were used to visualize the relationships between high-frequency keywords. The matrix plot is shown in Figure 7A. To combine similar rows into one single cluster, the rows of the initial matrix were reset, and each cluster was divided by a black horizontal line. In the matrix plot, the tree on the top and the tree on the left represent high frequency keyword associations. In the volcano plot in Figure $7 B$, the three-dimensional features of the data are directly shown. In this 3D image, 4 different peaks represent 4 different clusters numbered from 0 to 3. Those four clusters are as follows, Cluster 0: surgical treatment of OSA patients in children; Cluster 1: risk factors and diagnose of OSA in adults; Cluster 2: prevalence of 
Table 4 Ten most productive journals on obstructive sleep apnea

\begin{tabular}{|c|c|c|c|c|c|c|}
\hline Rank & Journal title & Article counts & $\begin{array}{l}\text { Total number of } \\
\text { citations }\end{array}$ & $\begin{array}{l}\text { Average number of } \\
\text { citations }\end{array}$ & IF (2020) & $\mathrm{H}$-index \\
\hline 1 & Sleep and Breathing & 1,297 & 9,286 & 7.16 & 2.816 & 43 \\
\hline 2 & Journal of Clinical Sleep Medicine & 815 & 8,594 & 10.54 & 4.062 & 51 \\
\hline 3 & Sleep Medicine & 808 & 5,719 & 7.08 & 3.492 & 43 \\
\hline 6 & Laryngoscope & 361 & 3,069 & 8.5 & 3.325 & 35 \\
\hline 7 & $\begin{array}{l}\text { International Journal of Pediatric } \\
\text { Otorhinolaryngology }\end{array}$ & 345 & 1,725 & 5 & 1.675 & 29 \\
\hline 8 & Chest & 279 & 4,599 & 16.48 & 9.41 & 34 \\
\hline
\end{tabular}

Table 5 Ten most cited publications on obstructive sleep apnea

\begin{tabular}{|c|c|c|c|c|c|}
\hline Rank & Title & Authors & Year & Journal & Total citations \\
\hline 3 & $\begin{array}{l}\text { "Long-term cardiovascular outcomes in men with } \\
\text { obstructive sleep apnea-hypopnea with or without } \\
\text { treatment with continuous positive airway pressure: an } \\
\text { observational study" (12) }\end{array}$ & Marin et al. & 2005 & Lancet & 1,566 \\
\hline 4 & $\begin{array}{l}\text { "Rules for scoring respiratory events in sleep: update of } \\
\text { the } 2007 \text { AASM" (13) }\end{array}$ & Berry et al. & 2012 & J Clin Sleep Med & 1,538 \\
\hline 5 & $\begin{array}{l}\text { "Increased prevalence of sleep-disordered breathing in } \\
\text { adults" (14) }\end{array}$ & Peppard et al. & 2014 & Am J Epidemiol & 1,359 \\
\hline 7 & $\begin{array}{c}\text { "Epidemiology of obstructive sleep apnea: a population } \\
\text { health perspective" (16) }\end{array}$ & Young et al. & 2002 & $\begin{array}{l}\text { Am J Respir Crit Care } \\
\text { Med }\end{array}$ & 1,194 \\
\hline 8 & $\begin{array}{l}\text { "Obstructive sleep apnea as a risk factor for stroke and } \\
\text { death" (17) }\end{array}$ & Yaggi et al. & 2005 & N Engl J Med & 973 \\
\hline 9 & $\begin{array}{l}\text { "Using the Berlin Questionnaire to identify patients at } \\
\text { risk for the sleep" (18) }\end{array}$ & Netzer et al. & 1999 & Ann Intern Med & 791 \\
\hline 10 & $\begin{array}{l}\text { "Association of sleep-disordered breathing, sleep apnea, } \\
\text { and hypertension in a large community-based study" (19) }\end{array}$ & Nieto et al. & 2000 & JAMA & 774 \\
\hline
\end{tabular}



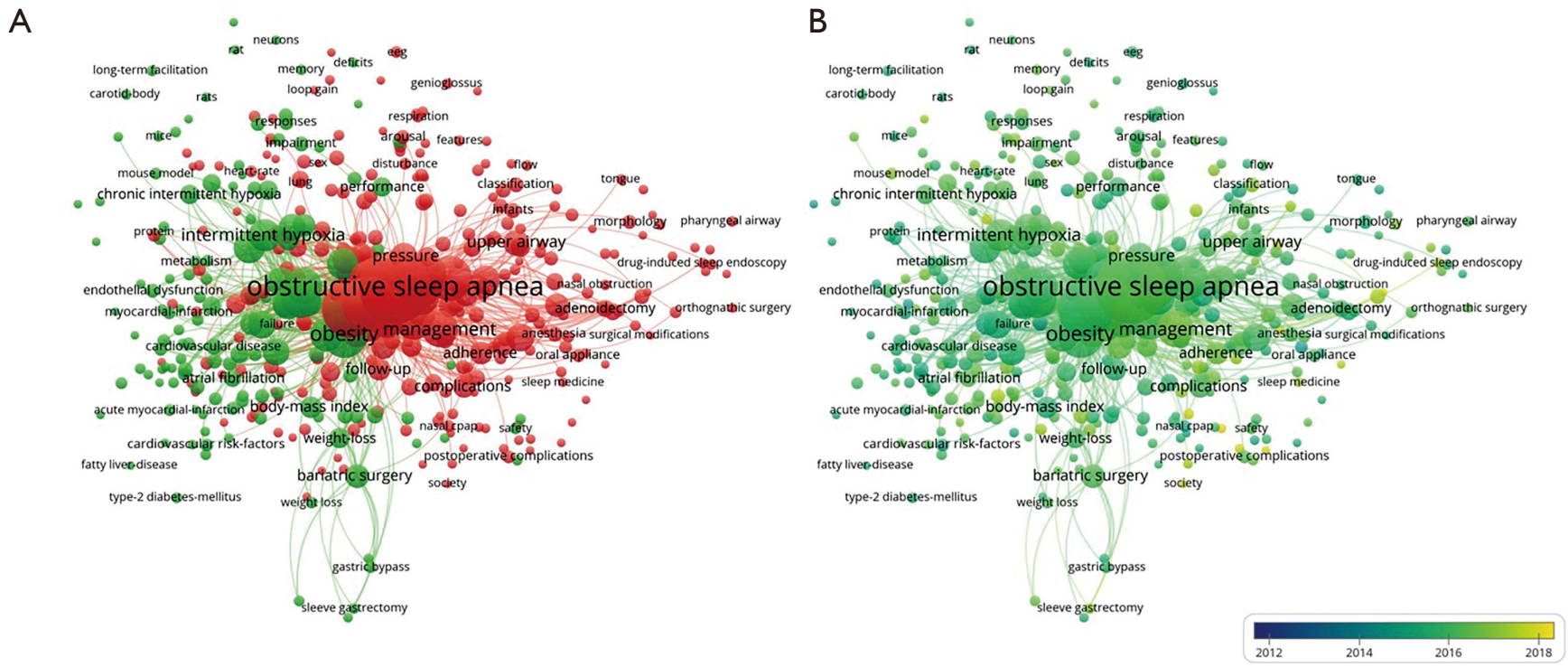

Figure 6 The mapping of keywords in obstructive sleep apnea studies. (A) most frequent keywords divided into two clusters according to clinical research (right, red) and basic research (left, green). (B) keywords visualized with the timeline of the inter-author collaboration.

OSA and positive airway pressure (PAP) treatment in OSA patients; Cluster 3: oxidative stress caused by intermittent hypoxia and complications of OSA such as cardiovascular disease and insulin-resistance.

\section{Discussion}

The clinical description of OSA has been found in many medical pieces of literature since the last century. However, it was not until the 1980s that the medical community widely recognized the clinical impact of OSA. Although public awareness of OSA has steadily increased since then, most patients remain undiagnosed (20). Since the last decade, improving living standards has encouraged more people to pay attention to the negative impact of sleep apnea. With the increasing number of patients visiting clinics for sleep problems, related research on sleep medicine has developed significantly. In this study, we reviewed 24,291 publications related to OSA globally from 2011 to 2020, and the results indicated a steady increase in the number of publications rising from $1,443(6.49 \%)$ in 2011 to 3,027 (13.6\%) in 2020. The high number of OSA publications in the last decade implies that OSA is a popular research hotspot, and its related fields have gained significant development.

The United States has the highest number of publications, with the most cited and influential publications, and its $\mathrm{H}$-index is much higher than that of other countries (H-index: 140). In other respects, four of the top 10 authors publishing the most papers and seven of the top 10 research institutions on sleep apnea are from the United States. In summary, the United States has been leading in the field of OSA research. Since 2018, China has experienced remarkable rapid growth in OSA publications, with the cumulative number of publications leaping to second place globally. However, China still falls short of the United States, Australia, and Canada citations and $\mathrm{H}$-index. We can also find that the United States is mostly involved in international collaboration through the inter-country collaboration map. The University of Pennsylvania is the most prolific, the University of Chicago ranks first in terms of the number of first authorships, and Harvard University is the most cited institution. Through institutional cocitation visualization, we can see that the United States research institutions have more collaboration. The depth of collaboration between countries and institutions has improved the overall level of OSA research in the United States, which may be why the United States has the strongest impact globally.

Sleep and Breathing have been the most published journals in the last decade, and Sleep is the journal with the highest impact (H-index: 64), where the second most cited article comes. Among the top 10 most prolific journals, our analysis shows that four journals belong to "Clinical Neurology", three belong to "Otorhinolaryngology". Others like Sleep 
Table 6 Hot keywords on obstructive sleep apnea

\begin{tabular}{|c|c|c|c|}
\hline Number & Keywords & Occurrences & Total link strength \\
\hline 1 & $\begin{array}{l}\text { Obstructive sleep } \\
\text { apnea }\end{array}$ & 9,562 & 13,467 \\
\hline 2 & $\begin{array}{l}\text { Positive airway } \\
\text { pressure }\end{array}$ & 3,098 & 12,983 \\
\hline 3 & Prevalence & 2,838 & 12,363 \\
\hline 4 & Obesity & 1,986 & 8,195 \\
\hline 5 & Children & 1,883 & 6,272 \\
\hline 6 & Hypertension & 1,477 & 6,549 \\
\hline 7 & Diagnosis & 1,389 & 5,434 \\
\hline 8 & Blood-pressure & 1,243 & 5,223 \\
\hline 9 & Management & 1,237 & 4,664 \\
\hline 10 & Adults & 1,224 & 5,126 \\
\hline 11 & Risk-factors & 1,172 & 4,949 \\
\hline 12 & Daytime sleepiness & 1,162 & 5,191 \\
\hline 13 & Quality-of-life & 1,097 & 4,266 \\
\hline 14 & Therapy & 1,091 & 4,693 \\
\hline 15 & Mortality & 1,024 & 4,626 \\
\hline 16 & Intermittent hypoxia & 1,011 & 3,704 \\
\hline 17 & $\begin{array}{l}\text { Cardiovascular- } \\
\text { disease }\end{array}$ & 952 & 4,301 \\
\hline 18 & Cpap & 950 & 4,444 \\
\hline 19 & Oxidative stress & 899 & 3,313 \\
\hline 20 & Surgery & 763 & 2,314 \\
\hline 21 & Insulin-resistance & 746 & 3,232 \\
\hline
\end{tabular}

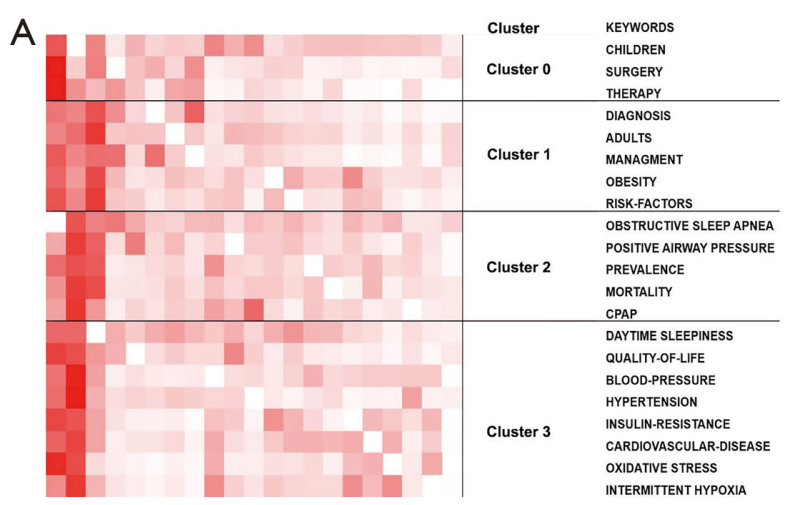

and Breathing belongs to "Clinical Neurology, Respiratory System," PLoS One belongs to "Multidisciplinary Sciences". Chest belongs to "Critical Care Medicine". According to the analysis of research categories in the WoS database, "Clinical Neurology", "Respiratory System" and "Neurosciences" are the top three categories with the most publications, accounting respectively for $24.47 \%, 16.42 \%$, and $10.22 \%$. Therefore, although publications on respiratory systems are already abundant, there are fewer influential journals related to OSA research. Journals on "Respiratory System" should pay more attention to high-quality publications related to OSA research. Among the top 10 cited articles, three are from the New England Fournal of Medicine. The most frequently cited paper is "The occurrence of sleepdisordered breathing among middle-aged adults," published by Young et al. in 1993, with 2,336 citations from NEFM.

Through clustering analysis and visualization of keywords, we summarized four hotspots related to OSA in the last decade, covering many aspects of basic research, clinical research, and epidemiology.

\section{Hotspots related to OSA in the last decade}

\section{Surgical treatment of OSA patients in children}

OSA prevalence in children is lower than that in adults, ranging from approximately $1.2 \%$ to $5.7 \%$ in the United States (21) OSA is one of the most serious sleep-disordered breathing disorders in children. Without timely diagnosis and effective intervention, it will lead to a series of serious complications, such as abnormal maxillofacial development (adenoid facies), behavioral abnormalities, learning

Figure 7 Research hotspots in obstructive sleep apnea field. (A) Visualization matrix. (B) Visualization of volcanoes with keyword biclustering. 
disabilities, growth retardation, neurocognitive impairment, endocrine, metabolic disorders, hypertension, pulmonary hypertension, and even increased risk of cardiovascular events in adulthood (22). Therefore, the diagnosis and treatment of OSA in children should be given more attention. The American Academy of Pediatrics provided guidelines in 2012 for treating children over the age of 1 year with OSA, excluding systemic disease and craniofacial disorders (21). This guideline states that adenotonsillectomy is the firstline therapy for children diagnosed with adenotonsillar hypertrophy in OSA. Most children respond well to adenotonsillectomy, but $20 \%$ still have refractory OSA after surgery, and these children may benefit from PAP therapy, weight loss, and intranasal corticosteroid therapy (23).

\section{Risk factors and diagnosis of OSA in adults}

Obesity is the most important reversible risk factor for OSA, with obese patients accounting for $41 \%$ of all OSA cases and $58 \%$ of moderate to severe OSA cases (24). Common risk factors for OSA include, but are not limited to, family history of OSA, retrognathia, treatment-resistant hypertension, congestive heart failure, atrial fibrillation, stroke, type 2 diabetes, polycystic ovary syndrome, acromegaly, and down syndrome (1).

At present, the methods of OSA diagnosis can be divided into three categories: PSG; HSAT and other diagnostic methods, including symptoms and signs, rhinopharyngeal endoscopy, imaging examination under drug-induced sleep, epworth sleepiness scale (ESS) and esophageal pressure examination. Misdiagnosis or underdiagnosis of OSA can be significantly detrimental to patients. Misdiagnosis or underdiagnosis of OSA can be significantly detrimental to patients. The 2017 AASM was updated with content and clinical recommendations, stating that PSG testing is necessary to diagnose OSA and is widely considered as the gold standard for OSA diagnosis (25).

\section{Prevalence of OSA and PAP treatment}

OSA prevalence is high in the general population and even higher in elderly men and those with high BMI. OSA prevalence and severity assessment results depend heavily on the heterogeneity in sampling methods and the diagnostic criteria used, thus contributing to the variation in reported prevalence. The prevalence of OSA (AHI $\geq 5$ ) in the general adult population (age $>18$ years) ranges from $9 \%$ to $38 \%$, with $13 \%$ to $33 \%$ among men and $6 \%$ to $19 \%$ among women. At the $\mathrm{AHI} \geq 15$ level, the prevalence ranged from $6 \%$ to $17 \%$ in the overall adult population and was higher in the elderly population (36\%) (26).

With the in-depth understanding of the pathophysiological mechanisms of OSA, treatment options have increased. However, PAP therapy is still the preferred treatment for adult OSA. According to "Treatment of Adult Obstructive Sleep Apnea with Positive Airway Pressure: An American Academy of Sleep Medicine Clinical Practice Guideline" (27), PAP therapy is recommended for adult OSA patients combining with excessive daytime sleepiness, reduced sleep-related quality of life, or hypertension. For adult OSA patients without obvious comorbidities, CPAP therapy after pressure titration in the sleep laboratory and family automatic continuous positive airway pressure (APAP) therapy are recommended. Long-term CPAP treatment reduces the risk of cardiovascular events (28-30), improves metabolic syndrome and endothelial dysfunction in patients with OSA, and reduces oxidative stress markers $(31,32)$. Compared with traditional CPAP therapy, APAP therapy has potential advantages. APAP can automatically adjust the treatment pressure according to the different physiological conditions of patients, such as drinking, changes in body position, and fluctuations in weight.

\section{Oxidative stress caused by intermittent hypoxia and complications of OSA such as cardiovascular disease and insulin-resistance}

The mechanism of OSA complications is multifactorial and is not yet fully defined, including but not limited to oxidative stress, sympathetic activation, activation of selective inflammatory molecular pathways, endothelial dysfunction, and metabolic dysregulation (33).

Animal models and clinical studies suggest that OSA aggravates obesity, inflammation, autonomic, vascular, cardiac dysfunction and exacerbates metabolic syndrome. The impact of OSA on the cardiovascular system has received wide attention and is considered to be an independent risk factor for cardiovascular diseases such as arterial hypertension, ischemic heart disease, heart failure and stroke (34). The combination of oxidative stress, sympathetic nerve activation, and inflammation may lead to endothelial dysfunction, hypertension, and arteriosclerosis. The effects of intermittent hypoxia have also contributed to the progression of insulin resistance and type 2 diabetes. Studies have shown that the development of type 2 diabetes in OSA patients may be due to the death of pancreatic $\beta$-cells caused by the increase of ROS levels caused by mitochondrial oxidative stress. 


\section{Trends of research hotspots for OSA}

It is also worth noting that in the last 5 years, keywords such as "Biomarkers", "Endoscopy", "Oral appliance", "Oropharyngeal exercises", "Bariatric surgery" are drawing special attention.

\section{Biomarkers of OSA}

Ideal OSA biomarkers are considered to serve as diagnostic measures, a means of assessing disease burden and severity, and a way to measure response to treatment with both sensitivity and specificity. Currently, the OSA biomarkers under research can be broadly classified into six groups, which include but are not limited to markers of inflammation (35-38) (CRP, IL-6, IL-8, TNF- $\alpha$ / $\mathrm{r} 1 / \mathrm{r} 2)$, cardiovascular and metabolic markers $(39,40)$ (total cholesterol, triglycerides, low-density lipoprotein cholesterol, apolipoprotein B, and glucose), endothelial dysfunction (41-44) (NO, eNOS, iNOS, ADMA), markers of oxidative stress (45-48) (TBARS, 8-isoprostane, AOPP, protein carbonyls), and other potential markers $(49,50)$ (Aß42, T-tau, P-tau, and melatonin). Although several candidate biomarkers have already emerged, showing potential to improve current diagnostic and therapeutic approaches, none of them may still be considered as a fully desirable biomarker at this stage.

\section{Endoscopy for OSA diagnosis}

PSG is considered the gold standard for OSA diagnosis and can differentiate pure snoring from OSA and determine the severity of OSA. Unfortunately, from a surgical perspective, PSG cannot provide a topographical assessment of the upper airway. Conversely, the accurate detection of the extent and pattern of airway collapse is essential for surgical planning in patients with OSA (51). Drug-induced sleep endoscopy (DISE) and awake endoscopy with Müller's maneuver (MM) have been used in clinical topographical assessment of the upper airway. Both DISE and MM can determine the site and pattern of airway collapse and can provide a three-dimensional anatomical topography of the affected area, helping surgeons to make proper surgical planning and decisions. Comparing with DISE, the limitation of $M M$, which is typically performed during wakefulness and often in an upright posture, is that the results may not correspond to what happens during supine sleep. However, patients with OSA also can benefit from it as it is an outpatient procedure, is performed without drug induction, and has less patient/hospital burden (52).

\section{Treatment for OSA}

The initial route of treatment depends on compliance of OSA patients and severity of the disease. Although PAP is the first treatment choice for adult OSA patients as mentioned above, there is still a growing interest in emerging therapies beyond PAP (53).

OSA is a well-recognized complication of obesity. Nonsurgical weight loss (medical, behavioral, and lifestyle interventions) may improve OSA outcomes, but long-term weight control remains challenging in obese patients (54). Bariatric surgery which includes laparoscopic Roux-en-Y gastric bypass (LRYGB), laparoscopic sleeve gastrectomy (LSG), and laparoscopic adjustable gastric banding (LAGB), offers a successful strategy for long-term weight loss and is associated with $60 \%$ likelihood of OSA resolution. Surgical modification of the upper airway is suitable for sever OSA patients that unable to tolerate PAP therapy. Modifying upper airway soft tissue and the bony structures of the face are the most common surgical procedures for managing OSA. Uvulopalatopharyngoplasty is the most extensively studied procedure, which involves resection of the uvula and part of the soft palate (55). Maxillomandibular advancement, which is to forward fixation of the facial skeleton by approximately $10 \mathrm{~mm}$ to enlarged the upper airway, is also a better-studied procedure (56). Significantly more reduced AHI than observation control also has been found after these upper-airway surgeries.

OSA treatment is developing toward individualization and diversification. It is noticed that upper-airway surgeries have been associated with significant perioperative adverse events (57), including severe neurologic injury and death. Therefore, publications upon surgery are reducing yearly. With the exploration of pathogenesis explanation and treatment options, targeted and less-invasive treatments have been increasingly used to improve patient compliance and outcomes. We note that publications on new treatments, such as MADs, oropharyngeal exercises, and hypoglossal pacemakers are growing steadily.

Currently, MADs are widely used to treat snoring and mild to moderate OSA as the primary therapy of choice for patients who are unwilling or unable to tolerate PAP, which are also simple, reversible, quiet, and cost-effective (58). MAD is a dental splint used to keep the mandible in a leaning-froward position. MADs push the mandible and tongue to the anterior position, thereby expanding the upper airway and reducing collapse during sleep. Bosi 
et al. demonstrated that MAD therapy acts mainly on passive collapsibility, and this therapy is effective in a low to moderate collapsibility range. MAD should be considered not only as an alternative to PAP but also as a potential complementary treatment to improve prognosis further (59).

In recent years, it has been found that patients with OSA tends to have impaired sensorimotor disorders located in the upper respiratory muscles. Oropharyngeal exercises and hypoglossal pacemakers have been followed with interest as treatments for upper airway muscles. Oropharyngeal exercises consist of a set of isometric and isotonic exercises involving the tongue, soft palate and lateral pharyngeal wall to strengthen them and to facilitate opening of the airway (60). Oropharyngeal exercises combined with mobile health (mHealth) app that use smartphones to teach severe OSA patients had obtained significant improvements in most metrics. A randomized controlled trial based on telemedicine with oropharyngeal exercises reached $53.4 \%$ reduction of AHI decreased from 44.7 (range, $33.8-55.6)$ to $20.88(14.02-27.7)$ events/hour $(\mathrm{P}<0.001)(61)$. Oropharyngeal exercises also can be an adjunct to other OSA treatments (62). Upper-airway patency is strongly correlated with the activation of the genioglossus muscle. Strollo et al., demonstrated that upper airway stimulation led to significant improvements in objective and subjective measures of OSA severity by a prospective cohort study (63). After treating for 12 months, the median AHI score decreased $68 \%$ (from 29.3 to 9.0 events/hour) $(\mathrm{P}<0.001)$; the ODI score decreased $70 \%$ (from 25.4 to 7.4 events/per hour) $(\mathrm{P}<0.001)$.

\section{Conclusions}

Over the past decade, increasing attention has been paid to global OSA-related research. The United States is dominating in the OSA research. China possesses a considerable publication number now, which has grown rapidly in the last decade. However, more attention to publication-quality is needed. Instead of traditional therapies, oral appliance, oropharyngeal exercises and many more new approaches are proven to benefit OSA patients and gradually becoming research hotspots.

\section{Acknowledgments}

Funding: The work was supported by Department of Human Resources and Social Security of Liaoning Province [Foundation of Distinguished Professor ([2015] No.153),
"100-1000-10000 Talent" Project-Outstanding Leaders Program (No. XLYC1805002)].

\section{Footnote}

Conflicts of Interest: All authors have completed the ICMJE uniform disclosure form (available at https://apm. amegroups.com/article/view/10.21037/apm-21-2237/coif). WW reports that she received support from Department of Human Resources and Social Security of Liaoning Province [Foundation of Distinguished Professor ([2015] No.153), "100-1000-10000 Talent" Project-Outstanding Leaders Program (No. XLYC1805002)]. The other authors have no conflicts of interest to declare.

Ethical Statement: The authors are accountable for all aspects of the work in ensuring that questions related to the accuracy or integrity of any part of the work are appropriately investigated and resolved.

Open Access Statement: This is an Open Access article distributed in accordance with the Creative Commons Attribution-NonCommercial-NoDerivs 4.0 International License (CC BY-NC-ND 4.0), which permits the noncommercial replication and distribution of the article with the strict proviso that no changes or edits are made and the original work is properly cited (including links to both the formal publication through the relevant DOI and the license). See: https://creativecommons.org/licenses/by-nc-nd/4.0/.

\section{References}

1. Lévy P, Kohler M, McNicholas WT, et al. Obstructive sleep apnoea syndrome. Nat Rev Dis Primers 2015;1:15015.

2. Gottlieb DJ, Punjabi NM. Diagnosis and Management of Obstructive Sleep Apnea: A Review. JAMA 2020;323:1389-400.

3. Seeger-Zybok RK, Klingelhöfer D, Groneberg DA. Global Risk Factor Evaluation of Obstructive Sleep Apnea in Relation to Research Activity and Socioeconomic Factors. Int J Environ Res Public Health 2020;17:6785.

4. Bosi M, Incerti Parenti S, Sanna A, et al. Non-continuous positive airway pressure treatment options in obstructive sleep apnoea: A pathophysiological perspective. Sleep Med Rev 2021;60:101521.

5. Lim DC, Mazzotti DR, Sutherland K, et al. Reinventing polysomnography in the age of precision medicine. Sleep 
Med Rev 2020;52:101313.

6. Zhou N, Ho JTF, Huang Z, et al. Maxillomandibular advancement versus multilevel surgery for treatment of obstructive sleep apnea: A systematic review and metaanalysis. Sleep Med Rev 2021;57:101471.

7. Choi JH, Cho SH, Kim SN, et al. Predicting Outcomes after Uvulopalatopharyngoplasty for Adult Obstructive Sleep Apnea: A Meta-analysis. Otolaryngol Head Neck Surg 2016;155:904-13.

8. Patil SP, Collop NA, Chediak AD, et al. Optimal NIV Medicare Access Promotion: Patients With OSA: A Technical Expert Panel Report From the American College of Chest Physicians, the American Association for Respiratory Care, the American Academy of Sleep Medicine, and the American Thoracic Society. Chest 2021;160:e409-17.

9. Venema JAMU, Rosenmöller BRAM, de Vries N, et al. Mandibular advancement device design: A systematic review on outcomes in obstructive sleep apnea treatment. Sleep Med Rev 2021;60:101557.

10. Young T, Palta M, Dempsey J, et al. The occurrence of sleep-disordered breathing among middle-aged adults. $\mathrm{N}$ Engl J Med 1993;328:1230-5.

11. Johns MW. A new method for measuring daytime sleepiness: the Epworth sleepiness scale. Sleep 1991;14:540-5.

12. Marin JM, Carrizo SJ, Vicente E, et al. Long-term cardiovascular outcomes in men with obstructive sleep apnoea-hypopnoea with or without treatment with continuous positive airway pressure: an observational study. Lancet 2005;365:1046-53.

13. Berry RB, Budhiraja R, Gottlieb DJ, et al. Rules for scoring respiratory events in sleep: update of the 2007 AASM Manual for the Scoring of Sleep and Associated Events. Deliberations of the Sleep Apnea Definitions Task Force of the American Academy of Sleep Medicine. J Clin Sleep Med 2012;8:597-619.

14. Peppard PE, Young T, Barnet JH, et al. Increased prevalence of sleep-disordered breathing in adults. Am J Epidemiol 2013;177:1006-14.

15. Peppard PE, Young T, Palta M, et al. Prospective study of the association between sleep-disordered breathing and hypertension. N Engl J Med 2000;342:1378-84.

16. Young T, Peppard PE, Gottlieb DJ. Epidemiology of obstructive sleep apnea: a population health perspective. Am J Respir Crit Care Med 2002;165:1217-39.

17. Yaggi HK, Concato J, Kernan WN, et al. Obstructive sleep apnea as a risk factor for stroke and death. N Engl J
Med 2005;353:2034-41.

18. Netzer NC, Stoohs RA, Netzer CM, et al. Using the Berlin Questionnaire to identify patients at risk for the sleep apnea syndrome. Ann Intern Med 1999;131:485-91.

19. Nieto FJ, Young TB, Lind BK, et al. Association of sleepdisordered breathing, sleep apnea, and hypertension in a large community-based study. Sleep Heart Health Study. JAMA 2000;283:1829-36.

20. Malhotra A, Ayappa I, Ayas N, et al. Metrics of sleep apnea severity: beyond the apnea-hypopnea index. Sleep 2021;44:zsab030.

21. Marcus CL, Brooks LJ, Draper KA, et al. Diagnosis and management of childhood obstructive sleep apnea syndrome. Pediatrics 2012;130:e714-55.

22. Lo Bue A, Salvaggio A, Insalaco G. Obstructive sleep apnea in developmental age. A narrative review. Eur J Pediatr 2020;179:357-65.

23. Garg RK, Afifi AM, Garland CB, et al. Pediatric Obstructive Sleep Apnea: Consensus, Controversy, and Craniofacial Considerations. Plast Reconstr Surg 2017;140:987-97.

24. Pugliese G, Barrea L, Laudisio D, et al. Sleep Apnea, Obesity, and Disturbed Glucose Homeostasis: Epidemiologic Evidence, Biologic Insights, and Therapeutic Strategies. Curr Obes Rep 2020;9:30-8.

25. Kapur VK, Auckley DH, Chowdhuri S, et al. Clinical Practice Guideline for Diagnostic Testing for Adult Obstructive Sleep Apnea: An American Academy of Sleep Medicine Clinical Practice Guideline. J Clin Sleep Med 2017;13:479-504.

26. Senaratna CV, Perret JL, Lodge CJ, et al. Prevalence of obstructive sleep apnea in the general population: A systematic review. Sleep Med Rev 2017;34:70-81.

27. Patil SP, Ayappa IA, Caples SM, et al. Treatment of Adult Obstructive Sleep Apnea with Positive Airway Pressure: An American Academy of Sleep Medicine Clinical Practice Guideline. J Clin Sleep Med 2019;15:335-43.

28. Patel N, Donahue C, Shenoy A, et al. Obstructive sleep apnea and arrhythmia: A systemic review. Int J Cardiol 2017;228:967-70.

29. Linz D, McEvoy RD, Cowie MR, et al. Associations of Obstructive Sleep Apnea With Atrial Fibrillation and Continuous Positive Airway Pressure Treatment: A Review. JAMA Cardiol 2018;3:532-40.

30. Lui MM, Tse HF, Lam DC, et al. Continuous positive airway pressure improves blood pressure and serum cardiovascular biomarkers in obstructive sleep apnoea and hypertension. Eur Respir J 2021;58:2003687. 
31. Abud R, Salgueiro M, Drake L, et al. Efficacy of continuous positive airway pressure (CPAP) preventing type 2 diabetes mellitus in patients with obstructive sleep apnea hypopnea syndrome (OSAHS) and insulin resistance: a systematic review and meta-analysis. Sleep Med 2019;62:14-21.

32. Feng $Y$, Zhang Z, Dong ZZ. Effects of continuous positive airway pressure therapy on glycaemic control, insulin sensitivity and body mass index in patients with obstructive sleep apnoea and type 2 diabetes: a systematic review and meta-analysis. NPJ Prim Care Respir Med 2015;25:15005.

33. Morrell MJ, Jackson ML, Twigg GL, et al. Changes in brain morphology in patients with obstructive sleep apnoea. Thorax 2010;65:908-14.

34. Xu J, Long YS, Gozal D, et al. Beta-cell death and proliferation after intermittent hypoxia: role of oxidative stress. Free Radic Biol Med 2009;46:783-90.

35. Nadeem R, Molnar J, Madbouly EM, et al. Serum inflammatory markers in obstructive sleep apnea: a metaanalysis. J Clin Sleep Med 2013;9:1003-12.

36. Motamedi V, Kanefsky R, Matsangas P, et al. Elevated tau and interleukin- 6 concentrations in adults with obstructive sleep apnea. Sleep Med 2018;43:71-6.

37. Bilal N, Kurutas EB, Orhan I, et al. Evaluation of preoperative and postoperative serum interleukin-6, interleukin-8, tumor necrosis factor $\alpha$ and raftlin levels in patients with obstructive sleep apnea. Sleep Breath 2021;25:819-26.

38. Cao Y, Song Y, Ning P, et al. Association between tumor necrosis factor alpha and obstructive sleep apnea in adults: a meta-analysis update. BMC Pulm Med 2020;20:215.

39. Qian Y, Zou J, Xu H, et al. Association of upper airway surgery and improved cardiovascular biomarkers and risk in OSA. Laryngoscope 2020;130:818-24.

40. Drager LF, Togeiro SM, Polotsky VY, et al. Obstructive sleep apnea: a cardiometabolic risk in obesity and the metabolic syndrome. J Am Coll Cardiol 2013;62:569-76.

41. Kheirandish-Gozal L, Wang Y, Duggan RC, et al. Nitric oxide production by monocytes in children with OSA and endothelial dysfunction. Clin Sci (Lond) 2014;127:323-30.

42. Peng L, Li Y, Li X, et al. Extracellular Vesicles Derived from Intermittent Hypoxia-Treated Red Blood Cells Impair Endothelial Function Through Regulating eNOS Phosphorylation and ET-1 Expression. Cardiovasc Drugs Ther 2021;35:901-13.

43. Depalo A, Carpagnano GE, Spanevello A, et al. Exhaled NO and iNOS expression in sputum cells of healthy, obese and OSA subjects. J Intern Med 2008;263:70-8.
44. Arlouskaya Y, Sawicka A, Głowala M, et al. Asymmetric Dimethylarginine (ADMA) and Symmetric Dimethylarginine (SDMA) Concentrations in Patients with Obesity and the Risk of Obstructive Sleep Apnea (OSA). J Clin Med 2019;8:897.

45. Cofta S, Winiarska HM, Płóciniczak A, et al. Oxidative Stress Markers and Severity of Obstructive Sleep Apnea. Adv Exp Med Biol 2019;1222:27-35.

46. Minoguchi K, Yokoe T, Tanaka A, et al. Association between lipid peroxidation and inflammation in obstructive sleep apnoea. Eur Respir J 2006;28:378-85.

47. Tóthová L', Celec P, Mucska I, et al. Short-term effects of continuous positive airway pressure on oxidative stress in severe sleep apnea. Sleep Breath 2019;23:857-63.

48. Jurado-Gámez B, Fernandez-Marin MC, GómezChaparro JL, et al. Relationship of oxidative stress and endothelial dysfunction in sleep apnoea. Eur Respir J 2011;37:873-9.

49. Bubu OM, Pirraglia E, Andrade AG, et al. Obstructive sleep apnea and longitudinal Alzheimer's disease biomarker changes. Sleep 2019;42:zsz048.

50. Javaheri S, Javaheri S. Update on Persistent Excessive Daytime Sleepiness in OSA. Chest 2020;158:776-86.

51. Jung AR, Koh TK, Kim SJ, et al. Comparison of level and degree of upper airway obstruction by Muller's maneuver and drug-induced sleep endoscopy in obstructive sleep apnea patients. Auris Nasus Larynx 2017;44:571-5.

52. Askar SM, Quriba AS, Hassan EM, et al. Positional Awake Endoscopy Versus DISE in Assessment of OSA: A Comparative Study. Laryngoscope 2020;130:2269-74.

53. Rotenberg BW, Murariu D, Pang KP. Trends in CPAP adherence over twenty years of data collection: a flattened curve. J Otolaryngol Head Neck Surg 2016;45:43.

54. Saunders KH, Igel LI, Tchang BG. Surgical and Nonsurgical Weight Loss for Patients with Obstructive Sleep Apnea. Otolaryngol Clin North Am 2020;53:409-20.

55. Sommer UJ, Heiser C, Gahleitner C, et al. Tonsillectomy with Uvulopalatopharyngoplasty in Obstructive Sleep Apnea. Dtsch Arztebl Int 2016;113:1-8.

56. Zaghi S, Holty JE, Certal V, et al. Maxillomandibular Advancement for Treatment of Obstructive Sleep Apnea: A Meta-analysis. JAMA Otolaryngol Head Neck Surg 2016;142:58-66.

57. Fouladpour N, Jesudoss R, Bolden N, et al. Perioperative Complications in Obstructive Sleep Apnea Patients Undergoing Surgery: A Review of the Legal Literature. Anesth Analg 2016;122:145-51.

58. Marklund M, Braem MJA, Verbraecken J. Update on oral 
appliance therapy. Eur Respir Rev 2019;28:190083.

59. Anandam A, Patil M, Akinnusi M, et al. Cardiovascular mortality in obstructive sleep apnoea treated with continuous positive airway pressure or oral appliance: an observational study. Respirology 2013;18:1184-90.

60. Lorenzi-Filho G, Almeida FR, Strollo PJ. Treating OSA: Current and emerging therapies beyond CPAP. Respirology 2017;22:1500-7.

61. O'Connor-Reina C, Ignacio Garcia JM, Rodriguez Ruiz E, et al. Myofunctional Therapy App for Severe Apnea-

Cite this article as: Pan L, Meng F, Zhang L, Shen H, Kong D, Wang W, Kang J. Global research trends of obstructive sleep apnea from 2011 to 2020: a 10-year bibliometric analysis. Ann Palliat Med 2022;11(5):1671-1686. doi: 10.21037/apm-21-2237
Hypopnea Sleep Obstructive Syndrome: Pilot Randomized Controlled Trial. JMIR Mhealth Uhealth 2020;8:e23123.

62. Camacho M, Certal V, Abdullatif J, et al. Myofunctional Therapy to Treat Obstructive Sleep Apnea: A Systematic Review and Meta-analysis. Sleep 2015;38:669-75.

63. Strollo PJ Jr, Soose RJ, Maurer JT, et al. Upper-airway stimulation for obstructive sleep apnea. N Engl J Med 2014;370:139-49. 